\title{
RISE: An R package for RISE analysis
}

DOI: $10.21105 /$ joss. 00846

\section{Software}

- Review ¿

- Repository ¿a

- Archive ¿

Submitted: 20 July 2018

Published: 08 August 2018

\section{License}

Authors of papers retain copyright and release the work under a Creative Commons Attribution 4.0 International License (CC-BY).

\section{David Wiley ${ }^{1,2}$}

1 Lumen Learning 2 Brigham Young University

\section{Summary}

Learning analytics provide designers of educational materials with the ability to ask and answer questions about the effectiveness of those materials in supporting student learning. However, copyright typically prevents designers from engaging in continuous improvement activities. Open educational resources provide designers of educational materials with copyright permission to revise and remix those materials, but they do not provide insights into where designers might most productively invest their continuous improvement efforts. Combining learning analytics with open educational resources opens the door to datadriven continuous improvement of educational materials. However, no open source tools exist to support designers in this time-intensive process.

rise is an $\mathrm{R}$ package that implements the resource inspection, selection, and evaluation (RISE) technique described in (Bodily, Nyland, \& Wiley, 2017). rise combines information about course learning outcomes, student use of learning materials aligned with learning outcomes, and student performance on assessments aligned with learning outcomes in order to automatically identify places where learning materials are not effectively supporting student learning. Automating the process of identifying areas for improvement allows designers to spend less of their time determining which learning materials need to be improved and more time actually making improvements to learning materials.

The source code for rise has been archived to Zenodo with the linked DOI: (Wiley, 2018)

\section{Acknowledgements}

I gratefully acknowledge contributions to the model implemented in rise made by my co-authors of the original paper, Bob Bodily and Rob Nyland.

\section{References}

Bodily, R., Nyland, R., \& Wiley, D. (2017). The rise framework: Using learning analytics to automatically identify open educational resources for continuous improvement. The International Review of Research in Open and Distributed Learning, 18(2). Retrieved from http://www.irrodl.org/index.php/irrodl/article/view/2952

Wiley, D. (2018). RISE package for r. doi:10.5281/zenodo.1318243 